\title{
Optimization of College Moral Education Based on Big Data
}

\author{
Xiaohui Zhu \\ Department of Ideological and political Science, Xi'an International University, \\ Xi'an710077, China \\ m15576385119@163.com
}

\section{Keywords: Big Data; Moral Education for University students; Optimization}

\begin{abstract}
Big Data technologies do not merely change our lifestyles and working modes, but also can be exploited to improve the moral education in universities, and thus they provide a good opportunity for the development of moral education. This paper aims to explore novel approaches from the perspective of Big Data to develop the moral education in universities and enhance its effectiveness. To this end, some feasible strategies are proposed which include optimizing the faculty construction of the moral education, setting up Big Data base and network learning platform, developing mobile apps of moral education for university students, which truly enhances the effectiveness of moral education for university students.
\end{abstract}

\section{Introduction}

With the development of information technology, Big Data has attracted great attention worldwide in recent years. In China, the number of Internet users grows rapidly. According to "The 41st statistical report on the development status of China's Internet", the number of Internet users in China reached 772 million, and the penetration rate reached $55.8 \%$ at the end of 2017, which means that the network information technology has been closely linked with the public lives and everyone lives and works with information technology. In simple terms, through the Internet, we need not go outside but can have knowledge of various news and important events occurring in the world, and can purchase products on different platforms. As a result, the total amount of data in the world present a spurt development, and the value embodied in big data today has received unprecedented attention. "A new era that pays more attention to the value of data is quietly coming" [1]. Compared to small data that traditional data researches actually deal with, big data possesses a massive data set and has a variety of data and is more real and objective. With the rising of big data, major changes have taken place in the way of life, work, and thinking of human beings and this has made the public lives and production methods more convenient, faster, and more efficient, as well as the environment for moral education in universities. The education methodologies will also undergo significant changes. How to actively adapt the new technology of big data on the development on moral education in and universities? How to use databased methods to fully grasp the true ideological trends and behaviors of college students, so as to optimize the strategies improving the moral education in universities? That is, the big data technologies provide a good opportunity for the development of moral education and the enhancement of its effectiveness.

\section{Impacts of Big Data on Moral Education in Universities}

Big data is a new revolution in data technology. It will have a full range of impacts on work, life, learning, and ways of thinking [2]. Humans have actually entered the era of data survival. In the era of data, everyone can't live without the Internet, which has also produced a huge amount of data. The data objectively and truly records every aspect of our daily life, and faithfully reflects our ideological 
conditions and values concepts. Our spiritual world are also objectively and fully reflected through data. Traditional data researches actually deal with small data and the big data technology makes a breakthrough in the research and will be able to understand ourselves in depth on the spiritual level. Before the era of big data, the data cannot be fully and truly collected due to the constraints of social conditions, so it is impossible to fully and accurately grasp people's subjective world and the objective world as well. But in the era of big data, the collection of data information can be comprehensively and truly collected. Analysis and research of big data through information technology can completely grasp people's ideological conditions and daily behavior habits and trajectories. It is no doubt that "the development of big data provides a new way for humans to understand the world and change the world, and to help us perceive and understand the world better[3].

In the era of big data, the object, environment, and technology of moral education have undergone tremendous changes. In the traditional investigations on moral education in universities, of the researchers are hard to overcome their subjectivities in the process of survey and design, not to mention in the entire investigation process, so the true statuses of the surveyed people are not completely accurate. Even though the surveyed people completely present themselves, the survey in the moral education researches cannot carry out an overall evaluation in a real sense. If the number of the survey samples is small, the information collected is not comprehensive and incomplete, and thus the accuracy of the investigation is difficult to be guaranteed.

In the era of big data, the researches on moral education in universities can rely on information technology to comprehensively and objectively understand the investigated students. First, big data is complete since it can collect information of the whole students and are no longer limited to sample surveys or partial surveys. Second, when big data records the individual's daily trajectory, the individuals are unaware of it, and thus they are difficult to hide their true situations as in previous ideological and political researches. Therefore, the data itself is objective and real and the analyses and researches based on such comprehensive, real, and accurate data is truly likely to have representativeness and typical results. From this viewpoint, the traditional analysis of moral education is difficult to be truly close to the truth. Meanwhile, there are many limitations of the traditional methods in the analysis, processing, and mining of data, which leads to the reduction of the reliability and validity of moral education in universities. Big data technology can quickly process and analyze massive data, so it can not only grasp the ideological status of the investigated people, but also capture their behavior trajectories which can be used to predict their ideological conditions and behaviors, and finally form dynamic understanding on the subjects. It follows that big data is significant for the development of moral education in universities, and it can provide high quality resources and methods for the extension and deepening of college moral education.

\section{Effects of Big Data Era on College Moral Education Methods}

The big data technology has changed people's way of understanding the world. Big data is a kind of "values and methodology" [4]. Big data will have a significant impact on the innovation of college moral education methods.

Promoting College Moral Education from Qualitatively to Quantitatively. The college moral education will be changed from qualitatively to quantitatively due to the big data technologies. In the analysis of current college moral education which follows the traditional education methods, the ideological problems of the college students are difficult to find, and some hidden problems cannot be effectively solved. "Big data has created unprecedented quantifiable dimensions for our lives"[5]. The application of big data technology in college moral education can overcome the drawbacks existing in the traditional education modes and can make the educational methods more scientific and rational. Based on the big data, we can analyze and dig the valuable conclusions to more accurately understand 
the ideological dynamics of the university students. Moral education faculties can better understand and evaluate the students and make the college moral education more effective.

College Moral Education Changes from Linear to Nonlinear Relationships. The methods of college moral education was greatly influenced by the era of big data, and it gradually changed from traditional linear relationship to nonlinear one. The linear relationship is a distinctive character of the traditional college moral education. Causality is used to analyze whether the students' thinking and behavior are correct and to solve the problems in the educational activities. In the era of big data, the data is voluminous. "We can hardly find the causal chain of each data."[6] The college moral education needs to carry out in-depth digging and analysis of the data involved by using the nonlinearity in order to quickly find the essence hidden in the data. Therefore, via big data technologies, college moral education can use the analysis of relevant factors of college students as the main method to strengthen the moral education in universities.

Expanding the College Moral Education from Locally to Globally. In the age of big data, the college moral education expands from the traditional local categories toward the global ones. Small data usually limits in the partial or local analysis when we analyze the students' ideological behaviors, namely, we cannot obtain an overall evaluation for the students, so these methods have obvious limitations compared with big data technologies. The local analysis of the moral education for individuals is easy to ignore the key issues and thus it limits the effectiveness of college moral education. Using the big data technologies, the college moral education can not only start from the global view, but also can analyze the individual idea and value, and further track his dynamic ideological trajectory, which makes the moral education have clear directions.

\section{Values of Big Data for College Moral Education}

"Big data brings out significant changes of our thinking mode from many aspects and gives a new direction of the thinking development" [7]. The applications of data to college moral education are of great importance to the improvement of pertinence and effectiveness of moral education in universities. Its importance is mainly reflected in the following aspects.

Enhancing the Pertinence of College Moral Education. In the past, the college moral education lacks of big data as a strong support, which makes the moral education less targeted so that the effectiveness of college moral education has been limited. In the era of big data, students have their own smart phones and their lives become intelligent. This requires that the college moral education constantly turns to be digital, so as to be consistent with the society development trend and the actual needs of students. As faculties working for college moral education, we can utilize the big data to analyze the ideological trends and value orientation of the students, find out the influence factors, and optimize the approaches of college moral education. In addition, through Appling big data, the college moral education will be more informative, and we can accurately predict the development and guide the healthy growth of students. Therefore, the large amounts of information based on big data can guide the college moral education.

Strengthen the Effectiveness of College Moral Education. College students often communicate through platforms such as QQ, WeChat, Weibo, and forums, and these activities will leave a massive data set. Through analyzing and mining of these massive data, we can achieve comprehensive and accurate understanding of their ideological conditions and behavioral habits. Therefore, college moral educators can rely on big data technologies to effectively and truly grasp the students' ideological activities and their development trajectories. Therefore, the educators can guide the ideological activities of college students so that the students' ideological level is imperceptibly improved, which helps students develop a sound ideological personality and makes college moral education effective. 


\section{Optimization of College Moral Education from the Perspective of Big Data}

Big data is a new way of understanding and grasping the world under the development of information technology. The great value demonstrated by big data shows that it has become a kind of core competitiveness [8]. Big data has its own superiority in terms of resources to discover the world. Applying big data to college moral education will effectively promote the optimization and innovation of moral education in universities. To this end, we can start from the following aspects.

Optimize the Faculty Construction for College moral Education. The current college moral educators are basically from humanities and social sciences. Indeed, they have good professional qualities and capabilities. However, their information technology capabilities are relatively lacking, which makes them feel helpless when applying the big data technologies. Therefore, we should recruit some faculties with good information network technology into the college moral education team. On one side, they optimize the faculty composition of moral education, but also solve the technical problems in college moral education and big data integration.

Strengthen Big Data Thinking. "Number is the origin of all things,"'[9] and data is an important way for human beings to realize the world. "Big data is the source for people to gain new cognitions and create new values.'[10] College moral educators should form big data thinking, deepen the understanding of the function and importance of big data, and actively learn big data technologies.

Actively Establish a Data Platform for College Moral Education. The daily lives of students form a variety of information and will be recorded in the database of the terminal, and then the information will be integrated by different departments. Based on the established college moral education platform and through analyzing the big data information, we can have the knowledge of the ideological status and behavior trajectories of the college students, and further improve the early warning capabilities and the effectiveness of college moral education.

Develop Mobile Apps of College Moral Education. The college moral education should make full use of the advantages of big data and actively develop the associated mobile apps. The mobile apps of the moral education can not only innovate the form of moral education, but also can attract the students' attention. In order to develop college moral education apps, we should analyze the platform data and explore the associated books, news and videos for moral education, which will not only create new forms, but also make the students accept moral edu6

\section{Conclusion}

As a new information technology, big data provides us a new thinking mode to recognize and understand the world, and also provide a broader perspective and a good foundation for the development of college moral education. However, it should be noted that in the college moral education, big data cannot be as the unique criterion and we should maintain the rationality and avoid the tool rationalism in practice.

\section{Acknowledgements}

The article is supported by the project of the "Thirteenth Five-Year Plan" for educational science of Shaanxi Province (Grant No. SGH16H270): Optimization of ideological and political education in universities from the perspective of big data.

\section{References}

[1] New Trends in the Development of Global Big Data. Guangming Daily, June 1, 2018. Url: http://www.edu.cn/xxh/ji_shu_ju_le_bu/dsj/201806/t20180601_1604305.shtml

[2] Steve Lohr. The Age of Big Data. The New York Times, February 11, 2012. 
[3] Xinrong Huang. The Development of Big Data to Scientific Epistemology. Natural Dialectics Research, 2014(9):84

[4] Viktor Mayer-Schönberger and Kenneth Cukier. Big Data: A Revolution That Will Transform How We Live, Work, Eamon Dolan/Mariner Books, 2014.

[5] Zhuangyu $\mathrm{Hu}$ and Liya Huang. The problems faced by undergraduates' ideological and political education in the era of big data and their solutions. Party Building and Ideological Education, 2014(7):65

[6] David Chandler. A World without Causation: Big Data and the Coming of Age of Posthumanism .Millennium: Journal of International Studies, 2015: 1-19

[7]Luciano Floridi. Big Data and Their Epistemological Challenge[J].Philosophy Technology, 2012(25):435-437

[8] Rui Zhang, Zhi Dong, and Xin Xia. Innovative Exploration of College Ideological and Political Education in the Era of Big Data. Party Building and Ideological Education, 2014(5):67

[9] Dunhua Zhao. General History of Western Philosophy: Volume I. Beijing: Peking University Press, 1996.

[10] Xiaoqin Liao and Jie Li. Innovation of College Moral Education in the Era of Big Data. Continued Education Research, 2016(11). 